\title{
Qingdao Amateur Football Club Present Situation and Development Countermeasure Research
}

\author{
Yi Jia ${ }^{1}$ \\ ${ }^{1}$ Department of Physical Education, Qingdao University of Science and Technology, Qingdao, China \\ Correspondence: Yi Jia, Department of Physical Education, Qingdao University of Science and Technology, \\ Qingdao 266061, China. E-mail: jyqust@163.com
}

Received: February 16, 2012

Accepted: March 20, 2012 Published: June 1, 2012

doi:10.5539/ass.v8n7p224

URL: http://dx.doi.org/10.5539/ass.v8n7p224

\begin{abstract}
This article through the questionnaire survey method, In the light of Qingdao city current amateur soccer development present situation and the existence question, Starting from the amateur football club, In personnel, funds, team coaches, venues and other aspects of analysis, Find out a feasible solution and Countermeasures, Qingdao City amateur football development provides referenced basis.
\end{abstract}

Keywords: Qingdao, amateur, football club, present situation, development countermeasure

\section{Questions}

In recent years, our country's amateur football development, Local amateur football league such as bamboo shoots after a spring rain emerged, These alliances are to carry out the main line of every kind of soccer game as football, Enjoying amateur football bring their own happiness. Qingdao as the country's most early established the city of football, Its rich football foundation also make more Qingdao people involved in amateur football in the big family of, With the 2005 Qingdao City League begins, The Qingdao amateur football also entered a new stage of development, City League to amateur football enthusiasts to provide a more reasonable and normative platform, Great also led the Qingdao citizens to participate in amateur football enthusiasm, The successful experience of Qingdao got the AFC highly, Known as the "Asian outlook" program model, Then in 2006 by folk initiative was established by the Qingdao Amateur Football League to promote rapid, Officially the Qingdao amateur football development to the climax, This article through to the Qingdao amateur football club present situation investigation and study, Hope Qingdao amateur football club development to provide some reasonable suggestions, In order to promote the Qingdao City amateur soccer sports development.

\section{Object and Method of Study}

\subsection{Study Object}

The article with Qingdao city 30 amateur football club as the object of study

\subsection{Research Methods}

\subsubsection{Literature}

By consulting with the related papers, books, newspapers and magazines, carries on the classified, refines the experience that can draw lessons from and method.

\subsubsection{Questionnaire}

In order to investigate the current situation of Qingdao City amateur football for the purpose, to the part of amateur soccer players, coaches for the survey questionnaire design, through the questionnaire in the form of various amateur football club of the related data, quantitative and qualitative analysis.

\subsubsection{Data Statistics}

The data obtained were statistically analyzed. 


\section{The Results of Studies}

\subsection{The Club Staff}

Table 1. The club staff

\begin{tabular}{cccc}
\hline & spontaneous & unit employees & unit staff and foreign staff \\
\hline quantity & 9 & 6 & 15 \\
percentage & $30 \%$ & $20 \%$ & $50 \%$ \\
\hline
\end{tabular}

Table 1 the club staff, divided into 3 forms, $30 \%$ clubs from the community of football fans spontaneously. $20 \%$ of the club by the unit 's own employees. The largest proportion of the unit staff and foreign staff composition model, the proportion of 50\%.Qingdao amateur football club personnel not same, This is the cause of amateur football clubs are not able to stability and development is one of the factors.

\subsection{Club Coaches Situation}

Table 2. Club coaches situation

\begin{tabular}{ccc}
\hline & fixed coach & no fixed coach \\
\hline quantity & 10 & 20 \\
percentage & $33 \%$ & $67 \%$ \\
\hline
\end{tabular}

From table 2 , there are $67 \%$ clubs is not fixed the coach, the club was in the game when the temporary command by the organizer to arrange, are arranged who first who come off the bench, and the club only occasionally temporary looking for someone to guide you. Only about 33\% of the club have formal long-term coach, the Qingdao amateur football club and there are many important organizational management work to need to strengthen.

\subsection{Main Economic Source of the Club}

Table 3. The main economic source of the club

\begin{tabular}{ccccc}
\hline & unit funding & membership fees & sponsors and membership fees & sponsors \\
\hline quantity & 11 & 4 & 12 & 3 \\
percentage & $37 \%$ & $13 \%$ & $40 \%$ & $10 \%$ \\
\hline
\end{tabular}

From table 3,37\% of the club's money from this unit funding, $13 \%$ Club funding is through players pay membership fees to raise money, $40 \%$ club is the players through the payment of contributions and from sponsorship combined to form a year of funding. 10\% Club rely on sponsors paid fees as expenses. Club funds is relatively unstable, funding has become the key factor during the process of development of the club.

\subsection{Club Contributions}

Table 4. Club dues situation

\begin{tabular}{ccccc}
\hline & dues & no dues & 500 yuan/year & $500-1000$ yuan/year \\
\hline quantity & 16 & 14 & 7 & 9 \\
percentage & $53 \%$ & $47 \%$ & $44 \%$ & $56 \%$ \\
\hline
\end{tabular}

From table $4,53 \%$ of the club's players to pay membership dues, $47 \%$ club players need not pay any fee to join the club activities. In the payment of contributions club has $44 \%$ Club annual fees in 500 yuan (RMB), 56\% club fee in 500-1000 yuan (RMB). Club dues to a certain extent in the team to attract high level players and coaches, should be in the reasonable arrangement of symbolic player dues collection.

\subsection{The Club Sponsors Case}

Table 5. The club sponsors situation

\begin{tabular}{ccccc}
\hline & sponsors & no sponsors & 20000 yuan/year & $20000-40000$ yuan/year \\
\hline quantity & 15 & 15 & 7 & 8 \\
percentage & $50 \%$ & $50 \%$ & $44 \%$ & $56 \%$ \\
\hline
\end{tabular}

Table 5 shows that, in the 30 amateur soccer club, has funded and sponsored club each accounted for $50 \%$. In 15 won the sponsorship of the club, 44\% Club sponsored in the amount of 20000 yuan (RMB), 56\% Club sponsored in the amount of 20000-40000 yuan (RMB). How to make good use of sponsors, and sponsors for better cooperation, is an important part in the development of the club.

\subsection{Amateur Competition Venue}

Qingdao City Amateur Football League each participating club venues by Alliance unites arrangement, respectively the Workers Stadium, Tiantai stadium outfield, Qiingdao University Institute of textile technology 
and Qiingdao University Teachers College, each game cost per team 200-300 yuan (RMB). Teams and venues are relatively few, cannot have satisfied football enthusiasts demand.

\section{Comparison and Analysis}

\subsection{Club Personnel System Stability}

A successful football club formed in personnel to maintain a relatively stable state, only the player reduces liquidity, in order to ensure that the team 's long-term development, team tactics, players between the tacit degree and team cohesion can be more mature and stable. Some players in the team to play for a period of time will switch to other teams, even some members hold several duty concurrently personally, participate in many clubs, the team that lost the collective sense of honor and the team's sense of belonging, resulting in a team scores fell and caused some unnecessary differences and contradictions. Therefore, amateur football club players can only ensure long-term in team effectiveness, avoid the loss and frequent change of players, the club can establish a good foundation, thereby protecting the club long-term orderly development.

\subsection{Club Hired Coaches Importance}

Coaches training during the game designers, business blueprint organizer and instructor. Coach a team for long-term sustainable development of key components, coaches can play an incentive role players, because of the limited level of amateur players, the error is very normal thing, coaches to improve a player's confidence is a great help, can inspire the team 's potential, allowing them to play their best. Coaches can also improve squad combat abilities, through reasonable Paibingbuzhen, allowing players to find a suitable location, allow players to learn from each other, play their own advantages, but also can reduce the differences between the players, reduce contradiction, enhance the team level and cohesion. The club should ask some professionals involved in their own team of construction, can be long-term and active in football teaching in teachers and experts, can also employ some recently retired occupation football player, because these people football and amateur players on the football awareness is distinct, believe that with these people's participation, club the management will be more standardized.

\subsection{Club Funding Source Reliability}

Amateur football club funds problem is the development of a huge factor in club. First of all, the enterprise should assure its subordinate amateur football club annual maintenance funds, guarantee the normal running of the club. In Shenzhen, Chengdu and amateur football development better city, unit funding is their main source of funding, the local enterprises to invest more in amateur football in the capital, they not only the football as a hobby, a leisure, fitness, entertainment, more important is the amateur football as a kind of enterprise culture construction.

If the enterprise of Qingdao can understand this point, so I think the enterprise to the amateur football inputs must now than it has substantially improved, so as to drive the Qingdao amateur football development. Secondly, the membership is fundamental to the development of the amateur football. In Qingdao, many teams are membership, but the club dues as a team the main source of funding is very undesirable, only charging a small fee can not support the club daily operation, often caused by the club staff loss and difficult to introduce a high level player.

Contributions will be produced between the player and the team unnecessary conflict, after all, Chinese amateur football club staff is relatively complex, social status and income has very big difference. In third, China Merchants on the team is very important, it is a team comprehensive strength reflect, need sponsors for the team to provide a good economic environment and material environment. Sports sponsorship is the essence of both resources or the interests of the exchange and cooperation, therefore, a successful sponsorship must be of mutual benefit, mutual gains, it is also affected by the legal system of market economy around. Sponsorship is not just" advertising" or "is a naming rights", but both resource reconfiguration of deep-level cooperation.

In short, the team money problems plaguing most of Qingdao amateur football club, if the club can put money to solve the problem, then the club will have greater development.

\subsection{Government Vigorously Support the Necessity}

Football is a very high degree of people's participation in sports, amateur football development quality of occupation football impact is very big, but the capacity is limited, there are many problems the masses involved in amateur football. The Qingdao amateur football league team has more than $70 \mathrm{branch}$, but the venue is only 5 , 6 block, every weekend to six pitches from morning to night every game, but there are still many teams because there is no venue could not arrange a match. Therefore, the Qingdao government departments concerned should 
be given to amateur football more support, provide more space so that the masses to participate in amateur football, and adjusting the venue rental fees, to the amateur football club create more funds to team building. Only in this way, can we build the Qingdao amateur football a good platform, create suitable environment for the development of amateur football, the football "of Qingdao city" reputation deserved.

\section{Conclusions and Suggestions}

1) Strong enterprises play to their initiative, the enterprises should have let subordinates Football Club long-term development goals, make enterprise more employees into the amateur football atmosphere, enhance staff soccer level, and according to the actual need to move into the professional football knowledge and level are relatively outstanding talent.

2) The club should be towards the higher goal of development, should employ active in football teaching experts and some recently retired occupation football player involved in the team's construction, making the club 's bylaws is more reasonable and more normative.

3) Enterprises should put the amateur football as a kind of enterprise culture construction, and gradually increase the investment to amateur football club. The club should play their role, make full use of oneself advantage, attract more sponsors and club for cooperation, as the club long-term development to lay a good foundation. At the same time, the club should make rational use of player dues, truly from the people, for the people.

4) Qingdao government departments concerned should be given to amateur football development more support and help, let more professional to amateur leagues and clubs and puts forward reasonable suggestions. In the field, the referee, funds, personnel and other aspects of the club to greater support, let the club can put more energy into its construction.

\section{References}

Qingdao: "Asian outlook". (2008). Qingdao Daily.

Wang, Wei, \& Li, Dongtao. (2009). Hebei provincial and municipal amateur football coaches' competence structure investigation and analysis. Popular Science, (2), 154.

Zhao, Houhua. (2010). A study on the status quo of amateur football training of adult group in Shenyang. Liaoning Sport Science and Technology, (6), 23-24.

Zhong, Fensheng. (2009). Sponsorship marketing password. China economy press. 